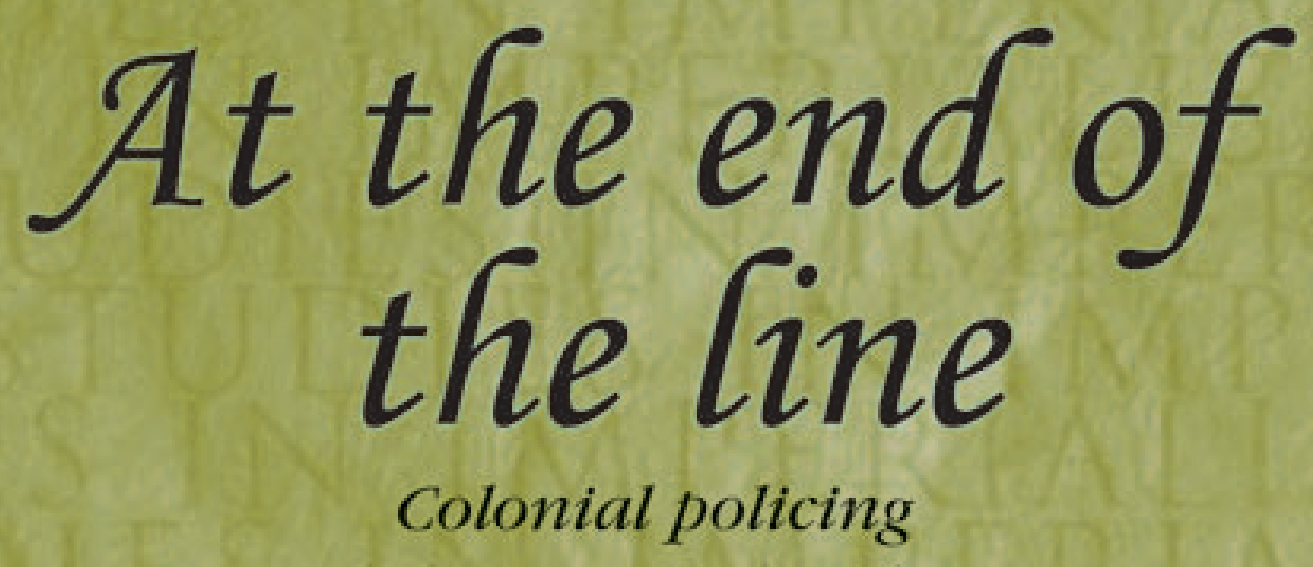
and the imperial endgame

$$
\text { 1945-80 }
$$

\title{
GEORGINA SINCLAIR
}

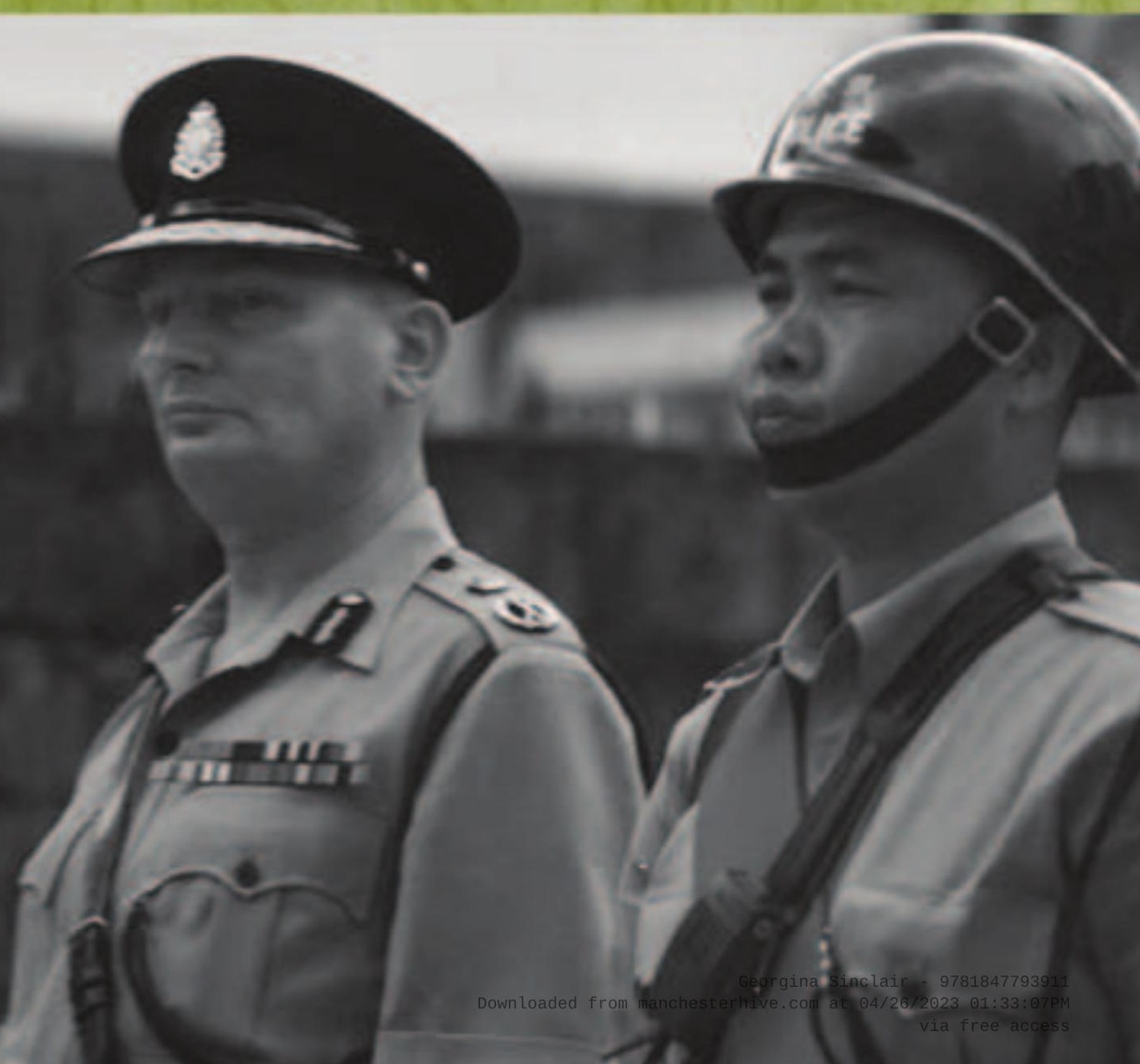

